\title{
CARBONATE FORMATION IN NON-AQUEOUS ENVIRONMENTS BY SOLID-GAS CARBONATION OF SILICATES
}

\author{
S.J. Day ${ }^{1,2}$, S.P. Thompson ${ }^{2}$, A. Evans ${ }^{1}$ and J.E. Parker ${ }^{2}$
}

\begin{abstract}
We have produced synthetic analogues of cosmic silicates using the Sol Gel method, producing amorphous silicates of composition $\mathrm{Mg}_{(x)} \mathrm{Ca}_{(1-x)} \mathrm{SiO}_{3}$. Using synchrotron X-ray powder diffraction on Beamline I11 at the Diamond Light Source, together with a newlycommissioned gas cell, real-time powder diffraction scans have been taken of a range of silicates exposed to $\mathrm{CO}_{2}$ under non-ambient conditions. The SXPD is complemented by other techniques including Raman and Infrared Spectroscopy and SEM imaging.
\end{abstract}

\section{Introduction}

Dust is present throughout the universe, existing in a wide variety of astrophysical environments and playing a major role in star and planet formation. Throughout their lifetime, dust grains are exposed to high levels of radiation and extreme temperatures, leading to the evolution of the amorphous, structurally disordered grains, formed within the atmospheres of evolved stars (Gail \& Sedlymayr 1998), to the highly processed materials that were present in the early solar nebula. We are investigating this processing and mineralization of grains using laboratory produced analogues of cosmic dust. In-situ synchrotron X-ray powder diffraction (SXPD) is conducted on Beamline I11 at Diamond Light Source (Thompson et al. 2009, 2011) and is complemented by SEM imaging, Raman and FTIR spectroscopy. This has relevance to the existence of carbonates in circumstellar environments that are believed to form through solid-gas interaction of cosmic silicates with gaseous $\mathrm{CO}_{2}$ at high temperatures (Rietmeijer et al. 2008). We describe preliminary proof-of-concept work which demonstrates that this process can indeed proceed.

${ }^{1}$ Astrophysics Group, Keele University, Staffordshire ST5 5BG, UK

2 Diamond Light Source, Harwell Campus, Didcot, Oxon OX11 0DE, UK 


\section{Experimental}

Beamline I11 is equipped to simulate extreme temperature and gas pressure conditions $\left(20<T<1000^{\circ} \mathrm{C}, 1-100\right.$ bar gas pressure), through the use of a cyberstar hot air blower and gas cell capillary holder (Parker et al. 2012; Thompson et al. these proceedings). Amorphous magnesium and calcium silicates of composition $\mathrm{Mg}_{x} \mathrm{Ca}_{1-x} \mathrm{SiO}_{3}$, where $0<x<1$, were produced in the laboratory as analogues of cosmic dust, using an adapted sol gel method (Thompson et al. 2012). To inhibit the direct formation of carbonate, the gels were dried in vacuo and the dried silicates stored under argon. Powdered samples were loaded into quartz capillaries in a gas cell and mounted onto the sample stage of the diffractometer. The heating and dosing of samples with $\mathrm{CO}_{2}$ was controlled remotely allowing real time, in-situ measurements to be taken. SXPD data were collected using a fast Position Sensitive Detector (Thompson et al. 2011), specifically designed for fast data collection. Data were collected at regular intervals as the samples were put under vacuum and then exposed to $\mathrm{CO}_{2}$ up to a pressure of 1 bar. While this is clearly higher than in circumstellar environments (so the reaction rate is correspondingly higher), the nature of the experimental setup requires such pressure in order to provide adequate diffusion of $\mathrm{CO}_{2}$ through the high packing density of the material in the capillary. After a number of scans at room temperature the hot air blower was introduced and the temperature was increased in steps of $50^{\circ} \mathrm{C}$, over a period of $\sim 1$ hour, up to a maximum of $900^{\circ} \mathrm{C}$; two 4 -s scans were taken at each temperature.

\section{Characterisation}

\subsection{Raman spectroscopy}

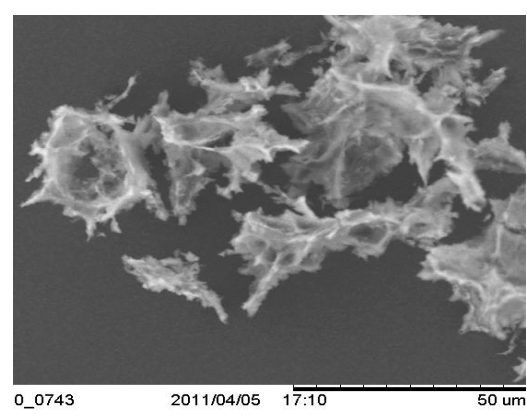

(a) SEM image, sample dried in vacuum

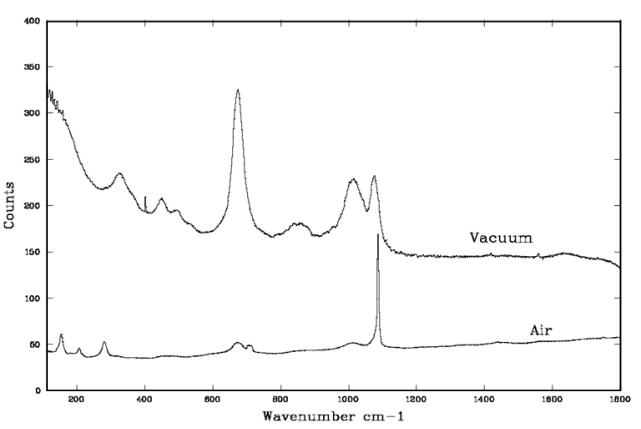

(b) Raman Spectra

Fig. 1. SEM image of vacuum dried sample and a comparison of Raman Spectra of $\mathrm{MgCaSiO}_{3}$ grains, dried in air and under vacuum.

The sol gels were dried in air and in vacuo, producing noticeably different end products. The gel dried in air produced solid, angular grains of a few $\mathrm{mm}$ to a few 
$\mathrm{cm}$ in size, varying from clear to white in colour depending on composition. On the other hand, gels dried in vacuo produce a very fine white powder, with SEM images showing a branch-like network structure with individual grains no larger than a few $\mu \mathrm{m}$ in size (see Fig. 1a).

Raman spectra show that there is also a compositional difference between the samples dried in air and those dried in vacuo (see Fig. 1b). The air-dried samples exhibit features of crystalline calcium carbonate (calcite) exhibiting characteristic features at $712 \mathrm{~cm}^{-1}$ and $1088 \mathrm{~cm}^{-1}$, while samples dried in vacuo show a predominately silicate composition with prominent features in the $670 \mathrm{~cm}^{-1}$ and $1000 \mathrm{~cm}^{-1}$ bands. This implies that the carbonation of the samples is due to the reaction of $\mathrm{Ca}$ with atmospheric $\mathrm{CO}_{2}$ during the drying phase.

\subsection{FTIR}

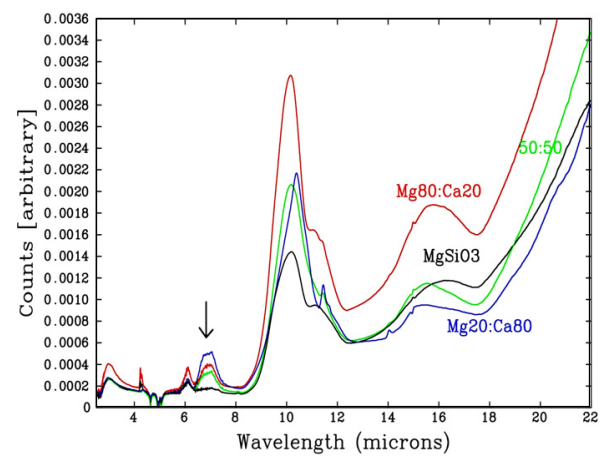

(a) FTIR Compositional

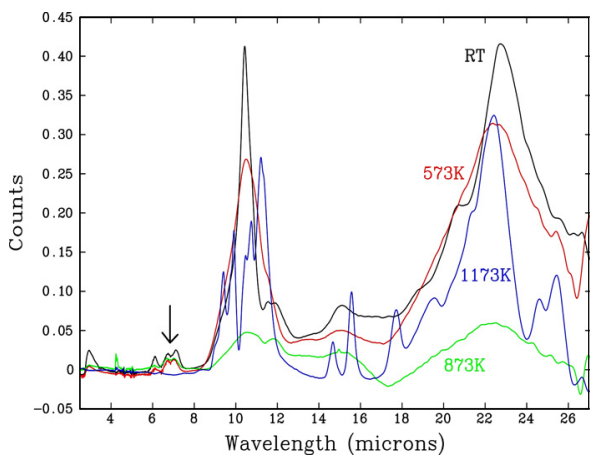

(b) FTIR heating

Fig. 2. Comparison of FTIR Spectra of $\mathrm{MgCaSiO}_{3}$ grains, of varying composition and temperature.

FTIR spectra of the samples were taken for a range of compositions and annealing temperatures. Figure $2 \mathrm{a}$ shows the comparison of four compositions, $x=0,0.2,0.8$ and 1 . A peak (arrowed) can be clearly seen at $7 \mu \mathrm{m}$ strengthening with increasing $\mathrm{Ca}$ content. Also with increasing $\mathrm{Ca}$ content, the broad silicate features around $11 \mu \mathrm{m}$ and $16 \mu \mathrm{m}$ seem to weaken. Figure $2 \mathrm{~b}$ shows the spectra of a $\mathrm{CaSiO}_{3}$ sample annealed at four different temperatures. Few differences are observed at temperatures of up to $873 \mathrm{~K}$, but note the disappearance of the $7 \mu \mathrm{m}$ feature and the rise of crystalline silicate features at temperatures greater than $873 \mathrm{~K}$. This indicates that any carbonate phase present within the sample becomes unstable at this temperature and breaks down.

\subsection{Synchrotron X-ray powder diffraction}

Figure 3a shows a sequence of $i n$-situ $\mathrm{SXPD}$ patterns of $\mathrm{Mg}_{0.5} \mathrm{Ca}_{0.5} \mathrm{SiO}_{3}$ exposed to $\mathrm{CO}_{2}$ at 1 bar pressure and heated to $1272 \mathrm{~K}$ over a period of a few hours. A feature 
indicative of calcite is present at low temperatures but disappears above $873 \mathrm{~K}$, again suggesting that the calcite phase is not stable at higher temperatures. The sample then begins to crystallize to diopside at just below $1173 \mathrm{~K}$. Reitveld refinement of the powder diffraction patterns, using the TOPAS-Academic software package (Coelho 2007), has provided information about the relative weight percentages of the diopside and calcite phases within the sample as it is being heated. This shows an inverse correlation of the two phases (see Fig. 3b).

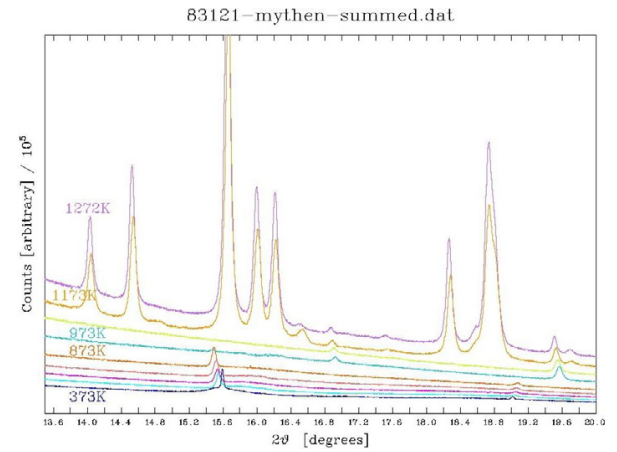

(a) Crystallisation sequence.

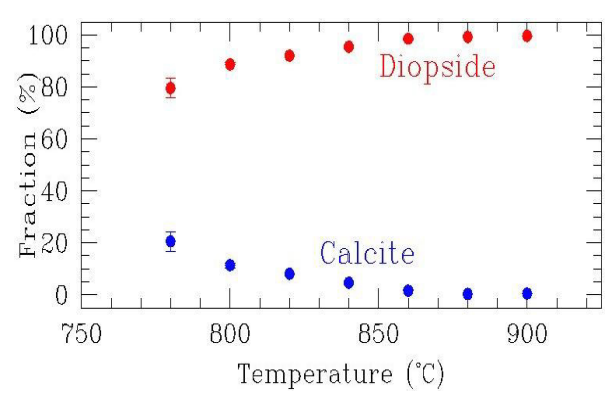

(b) Weight Percentages of Diopside and Calcite

Fig. 3. Sequence of powder diffraction patterns showing the structural evolution of a silicate sample and derived weight percentages of diopside and calcite phases.

\section{Results and conclusions}

Analysis of these data is still ongoing and the crystallization temperatures and effect of $\mathrm{CO}_{2}$ on the samples will be much better constrained through further experiments and analysis. At this stage we provide proof of physical principle regarding the formation of carbonates rather than a direct simulation of any astrophysical environment. However by knowing that the carbonate phase becomes unstable above $873 \mathrm{~K}$, we can begin to constrain the astrophysical environments in which carbonates would be able to form and survive.

\section{References}

Coelho, A., 2007, TOPAS-Academic [Computer Software], Version 4.1

Gail, H.P., \& Sedlymayr, E., 1998, Faraday Discussion, 109, 303

Parker, J.E., Potter, J., Thompson, S.P., Lennie, A., \& Tang, C., 2012, Mater. Sci. Forum, 706, 1707

Rietmeijer, F.J.M., Pun, A., Kimura, Y., \& Nuth, J.A., 2008, Icarus, 195, 493

Thompson, S.P., Parker, J.E., Potter. J., et al., 2009, Rev. Sci. Inst., 80, 075107

Thompson, S.P., Parker, J.E., Marchal, J., et al., 2011, J. Synchrotron Rad., 18, 637

Thompson, S.P., Day, S.J., Parker, J.E., Evans, A., \& Tang, C.C., 2012, J. Non Crystalline Solids, 358, 885 